\title{
The ENPP1 K121Q polymorphism is not associated with type 2 diabetes or obesity in the Chinese Han population
}

\author{
Teng Zhao ${ }^{1,5}$, Zhe Liu ${ }^{1,5}$, Di Zhang ${ }^{1}$, Yun Liu ${ }^{1}$, Yifeng Yang ${ }^{1}$, Daizhan Zhou ${ }^{1}$, Zhuo Chen ${ }^{1}$, Lan Yu ${ }^{1}$, \\ Zuofeng Zhang ${ }^{2}$, Guoyin Feng ${ }^{3}$, Lin $\mathrm{He}^{1,3,4}$ and $\mathrm{He} \mathrm{Xu}^{1}$
}

Type 2 diabetes (T2D) mellitus is a metabolic disorder characterized by chronic hyperglycemia and insulin resistance. It has been a worldwide public health problem, which is increasing rapidly, especially in developing countries such as China. The ectonucleotide pyrophosphatase/phosphodiesterase 1 (ENPP1) gene, also known as plasma cell membrane glycoprotein 1, has been reported by genetic association studies as being associated with T2D and obesity in various populations, such as Caucasian and African American. However, there are also some controversial results in Asian populations. Our study tried to examine the associations between ENPP1 and T2D and obesity. Rs1044498 (K121Q) and rs7754561 were genotyped in 1912 patients and 2041 control subjects through TaqMan technology on the ABI7900 system. They showed no statistical association with T2D, obesity or any metabolic quantitative traits. Our meta-analysis result was consistent with it. Our study did not replicate the positive association found previously and suggested that K121Q of ENPP1 might not have a major role in the susceptibility to T2D or obesity in the Chinese Han population.

Journal of Human Genetics (2011) 56, 12-16; doi:10.1038/jhg.2010.124; published online 28 October 2010

Keywords: chinese; ENPP1; obesity; SNP; type 2 diabetes

\section{INTRODUCTION}

Diabetes mellitus is a metabolic disorder characterized by chronic hyperglycemia with disturbances of carbohydrate, fat and protein metabolism. World Health Organization estimates that more than 180 million people worldwide have diabetes and the number is likely to double by 2030 . Meanwhile, the problem is considered to be much worse and more widespread in developing countries such as China. Of diabetic cases, $90 \%$ are type 2 diabetes (T2D) characterized by hyperglycemia due to a defect in insulin secretion or insulin resistance. The role of genetic factors of the illness has been consistently supported by population, family and twin studies. ${ }^{1-2}$ Genetic and genome-wide association studies in recent decades have identified many different candidate genes that are related to susceptibility in various populations. ${ }^{3-5}$

The ectonucleotide pyrophosphatase/phosphodiesterase 1 (ENPP1) gene, also known as plasma cell membrane glycoprotein 1 , localizes on chromosome 6q23.2, a region that has been reported to be being linked to obesity, ${ }^{6}$ serum insulin levels ${ }^{7}$ and $\mathrm{T} 2 \mathrm{D}^{8,9}$ in different populations. ENPP1 encodes for a type II transmembrane glycoprotein that inhibits insulin receptor (IR) tyrosine kinase activity ${ }^{10}$ and subsequent insulin signaling by a likely direct interaction with the $\alpha$-subunit of IR. ${ }^{11}$ The ENPP1 gene is upregulated in peripheral insulin target tissues, such as fibroblasts, muscle and adipose tissue, in insulin resistance subjects. ${ }^{12-14}$ The overexpression of ENPP1 increases insulin resistance in mammals. ${ }^{15}$ Allowing for insulin resistance is the earliest detectable defect in prediabetic individuals and a major feature of $\mathrm{T} 2 \mathrm{D} ;{ }^{16}$ ENPP1 is considered as a candidate gene for the etiological and pharmacological study of T2D.

A number of studies investigating the effects of ENPP1 on insulin resistance and pathogenesis of T2D, obesity and other metabolic syndromes have focused on the association with genetic variants. Pizzuti et al. ${ }^{17}$ first reported the strong association between a nonsynonymous single-nucleotide polymorphism (SNP) K121Q (rs1044498) on exon4 of ENPP1 and insulin resistance. A subsequent cellular transfection experiment showed that the $\mathrm{Q}$ allele was several fold more effective than the $\mathrm{K}$ allele in reducing insulin stimulation of IR autophosphorylation, IR substrate-1 phosphorylation, phosphatidylinositol 3-kinase activity, glycogen synthesis and cell proliferation. ${ }^{18}$

${ }^{1}$ Institute for Nutritional Sciences, Shanghai Institutes for Biological Sciences, Chinese Academy of Sciences, Shanghai, PR China; ${ }^{2}$ Department of Epidemiology, UCLA School of Public Health, Los Angeles, CA, USA; ${ }^{3}$ Bio-X Center, Key Laboratory for the Genetics of Developmental and Neuropsychiatric Disorders (Ministry of Education), Shanghai Jiao Tong University, Shanghai, PR China and ${ }^{4}$ Institutes of Biomedical Sciences, Fudan University, Shanghai, PR China

${ }^{5}$ These authors contributed equally to this work.

Correspondence: Dr Lin He, Bio-X Center, Shanghai Jiao Tong University, Hao Ran Building, 1954 Huashan Road, Shanghai 200030, PR China or Institutes of Biomedical Sciences Fudan University, 138 Yixueyuan Road, Shanghai 200032, PR China.

E-mail: helin@bio-x.cn or

Dr He Xu, Institute for Nutritional Sciences, Shanghai Institutes for Biological Sciences, Chinese Academy of Sciences, 294 Taiyuan Road, Shanghai 200031, PR China. E-mail: xuhe@sibs.ac.cn

Received 4 July 2010; revised and accepted 13 September 2010; published online 28 October 2010 
During the last decade, genetic association studies have found a positive association between K121Q and T2D in Caucasians and Indians, ${ }^{19-21}$ Tunisians, ${ }^{22,23}$ African Americans ${ }^{24}$ and Dominicans. ${ }^{25}$ The $\mathrm{Q}$ allele was also observed to increase the risk of obesity in the Caucasian population. ${ }^{26}$ However, contrary results were also reported between K121Q and T2D in the Asian and Caucasian population. ${ }^{27-33}$ In addition, recent genome-wide association studies have revealed a series of predisposing SNPs of $\mathrm{T} 2 \mathrm{D}$, which are mostly related to insulin secretion rather than to insulin resistance, ${ }^{34}$ in large-scale samples and gene pool, but no evidence of association, except one, ${ }^{21}$ between ENPP1 and T2D has been reported. ${ }^{3-5}$ In our study, we examined two representative SNPs of ENPP1, rs1044498 (K121Q) and rs7754561, and investigated the possible association between them and T2D and obesity in a Chinese case-control population, which had been the largest sample investigated in China so far. We also conducted a meta-analysis to provide a quantitative assessment of the collective evidence on the relationship between T2D (covering a total of 30,120 individuals) and ENPP1 variations.

\section{MATERIALS AND METHODS}

\section{Population and DNA preparation}

For the case-control investigation, 1912 unrelated T2D patients ( 785 male and 1127 female with a mean age of $63.8 \pm 9.0$ years; HbAlc, $7.4 \pm 1.6 \%$; fasting plasma glucose (FPG), $7.9 \pm 2.9 \mathrm{mmoll}^{-1}$; BMI, $25.2 \pm 3.4 \mathrm{~kg} \mathrm{~m}^{-2}$; waist-hip ratio, $0.89 \pm 0.06$, Table 1) were recruited from Shanghai, China. All patients were defined according to the World Health Organization criteria. Control subjects were enrolled from the same geographical region, with FPG concentration $<6.1 \mathrm{mmoll}^{-1}$ (635 male and 1406 female, with a mean age of $58.0 \pm 9.0$ years; HbAlc, $5.8 \pm 0.6 \%$; $\quad$ FPG, $4.9 \pm 0.7 \mathrm{mmoll}^{-1}$; $\quad$ BMI, $24.6 \pm 3.2 \mathrm{~kg} \mathrm{~m}^{-2}$; waist-hip ratio, $0.86 \pm 0.06$, Table 1). Obesity and nonobesity were defined as BMI $\geqslant 28 \mathrm{~kg} \mathrm{~m}^{-2}$ and BMI $<28 \mathrm{~kg} \mathrm{~m}^{-2}$, respectively, according to the Chinese criteria. ${ }^{35}$

A standard written informed consent, reviewed and approved by the Shanghai Ethical Committee of Human Genetic Resources, was obtained from all participating subjects who were provided with complete information about the study. High-molecular-weight genomic DNA was prepared from venous blood using the QuickGene 6101 Automatic DNA/RNA Extraction System (Fijifilm, Tokyo, Japan).

\section{Genotyping}

Rs1044498 and rs7754561 were genotyped through TaqMan technology on an ABI7900 system (Applied Biosystems, Foster City, CA, USA). All probes and primers were designed by the Assay-by-Design or Assay-on-Demand service of

Table 1 Clinical characteristics of the subject sample

\begin{tabular}{|c|c|c|c|}
\hline & $\begin{array}{c}\text { Type } 2 \text { diabetes } \\
\quad(n=1912)\end{array}$ & $\begin{array}{c}\text { Control } \\
(n=2041)\end{array}$ & $\mathrm{P}$ \\
\hline Age (years) & $63.8 \pm 9.0$ & $58.1 \pm 9.0$ & $<0.001$ \\
\hline BMI $\left(\mathrm{kg} \mathrm{m}^{-2}\right)$ & $25.3 \pm 3.4$ & $24.5 \pm 3.2$ & $<0.001$ \\
\hline Waist-to-hip ratio & $0.90 \pm 0.06$ & $0.86 \pm 0.06$ & $<0.001$ \\
\hline Fasting blood glucose (mmoll-1) & $8.1 \pm 2.9$ & $4.8 \pm 0.6$ & $<0.001$ \\
\hline Triglycerides $\left(\mathrm{mmol} \mathrm{I}^{-1}\right)$ & $1.9 \pm 1.6$ & $1.6 \pm 1.1$ & $<0.001$ \\
\hline Cholesterol (mmol l-1) & $4.5 \pm 0.9$ & $4.5 \pm 0.9$ & 0.365 \\
\hline $\mathrm{HDL}\left(\mathrm{mmol} \mathrm{I}^{-1}\right)$ & $1.2 \pm 0.3$ & $1.3 \pm 0.3$ & $<0.001$ \\
\hline $\operatorname{LDL}\left(\mathrm{mmol} \mathrm{I}^{-1}\right)$ & $2.8 \pm 0.8$ & $2.8 \pm 0.7$ & 0.009 \\
\hline Systolic blood Pressure $(\mathrm{mm} \mathrm{Hg})$ & $140.1 \pm 20.4$ & $132.0 \pm 19.3$ & $<0.001$ \\
\hline Diastolic blood Pressure $(\mathrm{mm} \mathrm{Hg})$ & $82.0 \pm 10.2$ & $81.1 \pm 10.1$ & 0.013 \\
\hline HbAlc (\%) & $7.5 \pm 1.6$ & $5.8 \pm 0.6$ & $<0.001$ \\
\hline
\end{tabular}

Abbreviations: BMI, body mass index; HbAlc, hemoglobin Alc; HDL, high density lipoprotein; LDL, low density lipoprotein.

Data are means \pm s.d.
Applied Biosystems. Standard PCR of $5 \mu \mathrm{l}$ was performed using TaqMan Universal PCR Master Mix reagent kits under the provided guidelines. Genotype data were obtained from more than $98 \%$ for rs 1044498 and from more than $91 \%$ for rs 7754561 of the DNA samples. The duplicate quality control samples (32 samples) were included and genotyped with $100 \%$ concordance.

\section{Statistical analysis}

The association analysis was assessed by logistic regression. All analyzing procedures were adjusted by sex, age and BMI. Homozygotes (1/1) for the additive model, heterozygotes (1/0) for the risk allele and homozygotes for the non-risk allele $(0 / 0)$ were encoded to an ordered categorical variable for genotype (2, 1 and 0$)$. The dominant model was defined as $1 / 1+1 / 0$ versus $0 / 0$ and the recessive model as $1 / 1$ versus $1 / 0+0 / 0$. Hardy-Weinberg equilibrium testing and allele, genotype and haplotype frequency analysis were carried out online on a robust and user-friendly software platform (http:// analysis.bio-x.cn/) $)^{36}$ developed by our lab. It was used to estimate LD and to compare the discrepancies of allele, genotype and haplotype frequencies on each locus between cases and controls using a $\chi^{2}$-test and odds ratio test. The difference in quantitative traits in the control group, including BMI, FPG, triglycerides, HbAlc and waist-to-hip ratio was analyzed using a general linear model, with BMI, FPG, triglycerides, HbAlc and waist-to-hip ratio as dependent variables, genotype as the independent variable and sex and age as covariates. Statistical analyses were performed using the SPSS (SPSS, Chicago, IL, USA) program.

Power calculations were performed using the $\mathrm{G}^{*}$ Power program. ${ }^{37}$ All $P$-values reported were two-tailed. Statistical significance was defined at $P<0.05$.

In the meta-analysis, Cochran's $\chi^{2}$-based Q-statistic test was performed to assess heterogeneity in all studies included. The random effects model, which yielded wider confidence intervals, was adopted when heterogeneity existed; otherwise both the fixed and random effects models were deemed appropriate. Combined ORs were calculated using the Mantel-Haenszel (fixed effects) and DerSimonian and Laird (random effects) methods and 95\% confidence intervals were constructed using Woolf's method. The significance $P$-value of overall ORs was determined using the Z-test. All calculations for the metaanalysis were carried out on Comprehensive Meta-Analysis software (Version 2.0, BIOSTAT, Englewood, NJ, USA).

\section{RESULTS}

Genotypic distributions of the two SNPs in cases and controls were in Hardy-Weinberg equilibrium $(P>0.05)$. In power calculations we found that the sample size had $>97 \%$ power for rs1044498 and $>99 \%$ for rs7754561 to detect a relatively weak gene effect $(\mathrm{OR}=1.2)$ with $\alpha \leqslant 0.05$.

However, we found no significant difference in allele or genotype frequencies between the total 1912 T2D patients and 2041 normal controls at either rs1044498 or rs7754561 under additive, dominant and recessive models before and after adjusting for sex and age (Table 2).

The estimation of linkage disequilibrium showed that rs1044498 and rs7754561 were not in strong LD with the standardized $\mathrm{D}^{\prime}=0.782$ and $r^{2}=0.049$. We further analyzed the frequencies of the haplotypes of the two SNPs above the common lowest frequency threshold (at least $3 \%$ frequency in both case and control groups) and still no significant association was found (Table 3).

Allowing for the important role of the ENPP1 gene in insulin resistance and the association widely reported with obesity and metabolic syndromes, we performed the same logistic regression model analysis for obesity and non-obesity (Table 4) in controls, and specifically examined the relationship between two SNPs and BMI, FPG, triglycerides, HbAlc, waist-to-hip ratio in the control group by general linear model analysis (Table 5). We found a marginal significance of allele association between rs7754561 and obesity $(P=0.045)$, although it was eliminated after correction for multiple 
Table 2 Allele and genotype distributions of the SNPs in cases and controls

\begin{tabular}{|c|c|c|c|c|c|c|c|c|c|c|}
\hline \multirow[b]{2}{*}{ SNPS } & \multirow[b]{2}{*}{$\begin{array}{l}\text { Risk } \\
\text { allele }\end{array}$} & \multicolumn{2}{|c|}{ Risk-allele frequencies } & \multirow{2}{*}{$\begin{array}{l}\text { Unadjusted } \\
\text { OR }(95 \% \mathrm{Cl})\end{array}$} & \multirow[b]{2}{*}{ Genotype } & \multicolumn{2}{|c|}{ Genotype distribution } & \multicolumn{3}{|c|}{ Adjusted by sex, age and BMI } \\
\hline & & $\begin{array}{l}\text { Control } n \\
\text { (frequency) }\end{array}$ & $\begin{array}{c}T 2 D n \\
\text { (frequency) }\end{array}$ & & & $\begin{array}{l}\text { Control } n \\
\text { (frequency) }\end{array}$ & $\begin{array}{c}T 2 D n \\
\text { (frequency) }\end{array}$ & $\begin{array}{l}\text { Additive model } \\
\text { OR }(95 \% \mathrm{Cl})\end{array}$ & $\begin{array}{c}\text { Dominant model } \\
\text { OR }(95 \% \mathrm{Cl})\end{array}$ & $\begin{array}{c}\text { Recessive model } \\
\text { OR }(95 \% \mathrm{Cl})\end{array}$ \\
\hline \multirow[t]{3}{*}{ rs1044498 } & C & $423(0.11)$ & $439(0.12)$ & $0.89(0.77-1.02)$ & CC & $19(0.01)$ & $23(0.01)$ & $1.15(0.97-1.34)$ & $1.15(0.98-1.36)$ & $1.33(0.70-2.54)$ \\
\hline & & & & $P_{\text {frequency }}=0.10$ & $\mathrm{CA}$ & $385(0.19)$ & $393(0.21)$ & $P_{\text {add }}=0.08$ & $P_{\mathrm{dom}}=0.09$ & $P_{\text {rec }}=0.39$ \\
\hline & & & & & AA & $1610(0.80)$ & $1463(0.78)$ & & & \\
\hline & & & & & $A A$ & $296(0.16)$ & $300(0.17)$ & & & \\
\hline
\end{tabular}

Abbreviations: $\mathrm{Cl}$, confidence interval; OR, odds ratio; SNP, single nucleotide polymorphism; T2D, type 2 diabetes.

Table 3 Estimated haplotype analysis in the case-control samples

\begin{tabular}{lcccc}
\hline Haplotype & $\begin{array}{c}\text { Type 2 diabetes } \\
n \text { (frequency) }\end{array}$ & $\begin{array}{c}\text { Control } n \\
\text { (frequency) }\end{array}$ & Fisher's P & $\begin{array}{c}\text { Odds ratio } \\
(95 \% \mathrm{Cl})\end{array}$ \\
\hline A-A & $1353.25(0.40)$ & $1434.82(0.39)$ & 0.49 & $1.04(0.94 \sim 1.14)$ \\
A-G & $1680.75(0.49)$ & $1900.18(0.51)$ & 0.06 & $0.92(0.83 \sim 1.01)$ \\
C-G & $362.25(0.11)$ & $340.82(0.09)$ & 0.05 & $1.17(1.00 \sim 1.37)$
\end{tabular}

Abbreviation: $\mathrm{Cl}$, confidence interval.

Haplotype analysis excluded those with less than $3 \%$ estimated haplotype probability. The individual haplotype frequency differences between cases and controls were calculated using SHEsis software platform. For each haplotype, alleles are arranged by rs1044498-rs7754561 orderly.

testing. It reported a significant tendency, whereas it was likely to be a statistical false-positive result. In addition, further genotype analysis suggested no significant associations with obesity in additive, dominant and recessive models after adjusting by sex and age. Further, no significant associations between polymorphisms of ENPP1 and metabolic quantitative traits were observed after adjusting by sex and age.

Furthermore, we conducted a meta-analysis consisting of all available published studies (before Oct 2009) and our present data to attain sufficient power to quantitatively assess the collective evidence on the associations of ENPP1 variants with T2D. The analysis was adjusted for age and gender. We found no heterogeneity of ORs across these studies $(P=0.098)$. Overall, the pooled OR for T2D was not statistically significant for the risk alleles of K121Q of the ENPP1 gene (pooled $\mathrm{OR}=1.068, P=0.064$ ) as shown in Figure 1 . In addition, we also conducted a meta-analysis in the set of Asian populations, including Chinese, Japanese and Korean. There was no heterogeneity $(P=0.716)$. The pooled ORs and $P$-value of Asians showed no association between $\mathrm{K} 121 \mathrm{Q}$ and $\mathrm{T} 2 \mathrm{D}$ (pooled $\mathrm{OR}=1.085, P=0.100$ ) as shown in Figure 2.

\section{DISCUSSION}

Diabetes mellitus has reached epidemic proportions and affects more than 180 million individuals worldwide. Global estimates for the year 2010 predict a further growth of almost 50\%, with the greatest increases in the developing countries of Africa, Asia and South America. ${ }^{38}$ The problem is becoming serious, especially in China, a country with a population of 1.3 billion. The number of T2D patients is going to be extremely huge in a coming-of-age society. According to the World Health Organization criteria, diabetes mellitus is a metabolic disorder characterized by chronic hyperglycemia, with disturbances of carbohydrate, fat and protein metabolism. This clinical phenomenon is likely to be partially attributable to impaired insulin secretion and insulin resistance in which some key genes have important roles. Over the past decade, genetic and gnome-wide association studies on TCF7L2, SLC3OA8, HHEX, FTO, PPARG, KCNJ11 and ENPP1 have suggested a possible relationship between allele and genotype frequencies and pathogenesis of T2D.

The ENPP1 gene, also known as plasma cell membrane glycoprotein 1, encodes for a type II transmembrane glycoprotein, which inhibits the IR and subsequent insulin signaling. When overexpressed in peripheral insulin target tissues, it is involved in human insulin resistance. The molecular mechanism responsible for the phenomenon was first reported to be associated with a non-synonymous SNP K121Q17, which enabled the Q allele for a 'gain-of-function' effect several fold more effective than the $\mathrm{K}$ allele in reducing insulin stimulation of IR autophosphorylation, IR substrate-1 phosphorylation, phosphatidylinositol 3-kinase activity, glycogen synthesis and cell proliferation. ${ }^{18}$ Further, genetic association analyses have supported and suggested that polymorphisms of ENPP1 are associated with the risk of T2D, obesity and a series of metabolic syndromes.

However, we failed to replicate a positive association between rs1044498, rs7754561 and T2D or obesity (except a marginal allele significance for rs7754561 without multiple correction) in the Chinese Han population. The positive associations were often reported from White ${ }^{19,39,40}$ and African ${ }^{24}$ populations; however, conversely, negative results were found recently in Moroccan, ${ }^{41}$ Chinese, ${ }^{28}$ Japanese, ${ }^{29}$ and Korean $^{32}$ populations, as indicated in Figure 2. Indeed, population heterogeneity should be considered, especially for a complex metabolic disease. Moreover, unlike a single gene disease, T2D and obesity should be attributable to multifactorial pathogenesis caused by alterations in many gene products. Our study suggested that K121Q of ENPP1 might not have a major role in susceptibility to T2D or obesity, but we cannot completely rule out the possible effects of ENPP1. ENPP1 may function through other polymorphisms among the Chinese. On the other hand, association studies are mainly concerned with the minor effect of genes or genotypes; hence samples have to be large enough and have sufficient statistical power to deliver satisfactory results. Previous studies with positive results have been based on several relatively small samples; hence further studies should have larger and ethnos-concerned samples. Our investigation on ENPP1 constitutes the largest sample to date relating to T2D and obesity in the Chinese population.

In addition, we examined the relationship of two SNPs and BMI, FPG, triglycerides, HbAlc and waist-to-hip ratio in the control group by general linear model analysis, considering that the physiological conditions of patients might be altered by medicines and treatments. None of them showed significant association with all these metabolic quantitative traits. 
Table 4 Allele and genotype distributions of the SNPs in the control subjects with obesity and non-obesity

\begin{tabular}{|c|c|c|c|c|c|c|c|c|c|c|}
\hline \multirow[b]{2}{*}{ SNPS } & \multirow[b]{2}{*}{$\begin{array}{l}\text { Risk } \\
\text { allele }\end{array}$} & \multicolumn{2}{|c|}{ Risk-allele frequencies } & \multirow{2}{*}{$\begin{array}{l}\text { Unadjusted } \\
\text { OR (95\% Cl) }\end{array}$} & \multirow[b]{2}{*}{ Genotype } & \multicolumn{2}{|c|}{ Genotype distribution } & \multicolumn{3}{|c|}{ Adjusted by sex and age } \\
\hline & & $\begin{array}{l}\text { Obesity } n \\
\text { (frequency) }\end{array}$ & $\begin{array}{l}\text { Non-obesity } \\
n \text { (frequency) }\end{array}$ & & & $\begin{array}{l}\text { Obesity } n \\
\text { (frequency) }\end{array}$ & $\begin{array}{l}\text { Non-obesity } \\
n \text { (frequency) }\end{array}$ & $\begin{array}{c}\text { Additive model } \\
\text { OR }(95 \% \mathrm{Cl})\end{array}$ & $\begin{array}{l}\text { Dominant model } \\
\text { OR }(95 \% \mathrm{Cl})\end{array}$ & $\begin{array}{c}\text { Recessive model } \\
\text { OR }(95 \% \mathrm{Cl})\end{array}$ \\
\hline \multirow[t]{3}{*}{ rs1044498 } & C & $64(0.11)$ & $508(0.10)$ & $1.09(0.82-1.44)$ & CC & $2(0.01)$ & $17(0.01)$ & $1.08(0.81-1.44)$ & $1.11(0.82-1.52)$ & $0.68(0.16-2.97)$ \\
\hline & & & & $P_{\text {frequency }}=0.56$ & $\mathrm{CA}$ & $60(0.21)$ & $325(0.19)$ & $P_{\text {add }}=0.60$ & $P_{\text {dom }}=0.49$ & $P_{\text {rec }}=0.61$ \\
\hline & & & & & AA & $224(0.78)$ & $1386(0.80)$ & & & \\
\hline rs7754561 & & & & & $\mathrm{AA}$ & $34(0.13)$ & $262(0.16)$ & & & \\
\hline
\end{tabular}

Abbreviations: $\mathrm{Cl}$, confidence interval; OR, odds ratio; SNP, single nucleotide polymorphism.

Table 5 Associations between the SNPs and quantitative traits in control subjects

\begin{tabular}{|c|c|c|c|c|c|c|c|}
\hline \multirow[t]{4}{*}{ Rs1044498 } & $\mathrm{A} / \mathrm{C}$ & BMI $\left(\mathrm{kg} \mathrm{m}^{-2}\right)$ & $24.3(22.3-26.5)$ & $24.5(22.6-26.7)$ & $24.8(22.9-26.6)$ & 0.071 & 0.454 \\
\hline & & FPG $\left(\mathrm{mmol}^{-1}\right)$ & $4.90(4.51-5.26)$ & $4.86(4.50-5.23)$ & $4.74(4.44-5.00)$ & -0.062 & 0.062 \\
\hline & & $\mathrm{HbAlc}$ & $5.81(5.47-6.10)$ & $5.77(5.40-6.12)$ & $5.89(5.41-6.13)$ & -0.041 & 0.279 \\
\hline & & W/h & $0.86(0.82-0.90)$ & $0.86(0.82-0.91)$ & $0.86(0.82-0.90)$ & 0.004 & 0.186 \\
\hline \multirow[t]{3}{*}{ rs7754561 } & $A / G$ & BMI $\left(\mathrm{kg} \mathrm{m}^{-2}\right)$ & $24.1(22.0-26.2)$ & $24.3(22.3-26.5)$ & $24.5(22.3-26.7)$ & 0.269 & 0.054 \\
\hline & & $\mathrm{HbAlc}$ & $5.82(5.44-6.13)$ & $5.82(5.47-6.13)$ & $5.81(5.47-6.09)$ & 0.001 & 0.938 \\
\hline & & $\mathrm{w} / \mathrm{h}$ & $0.86(0.82-0.89)$ & $0.86(0.82-0.90)$ & $0.86(0.82-0.90)$ & 0.002 & 0.342 \\
\hline
\end{tabular}

Abbreviation: BMI, body mass index; FPG, fasting plasma glucose; HbAlc, hemoglobin Alc; RegCo, regression coefficient; SNP, single nucleotide polymorphism; Trig, triglycerides; w/h, waist-to-hip ratio. Data are median (1st-3rd quartile). $P$-values were derived using the additive model adjusted by sex and age.

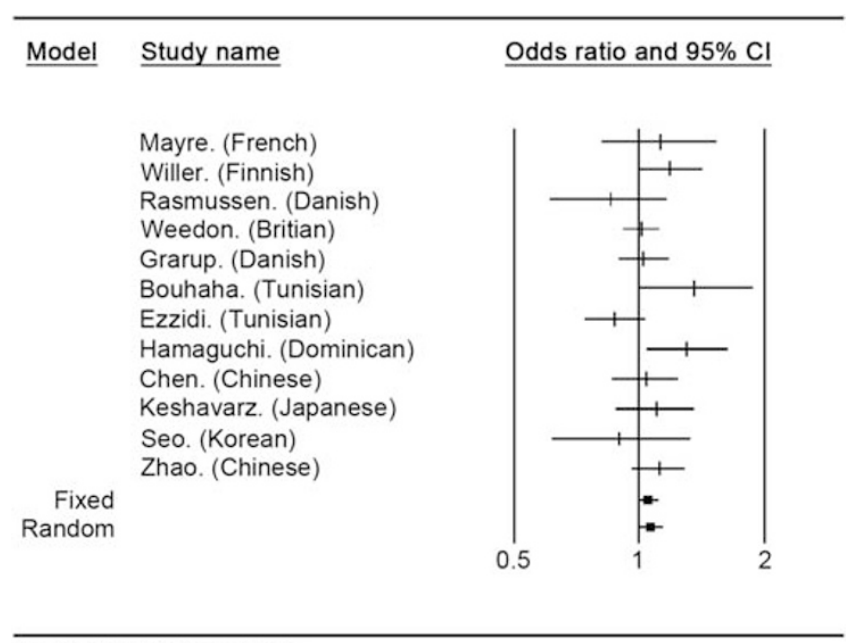

ENPP1 K121Q and T2D

Figure 1 Meta-analysis of ENPP1 K121Q and type 2 diabetes.

One limitation of our study is that the two tagged SNPs we selected could not cover the whole region of the ENPP1 gene, which is approximately $87 \mathrm{~kb}$. Another limitation is that we did not obtain accurate HOMA-IR data, for ENPP1 is reported as being related to insulin resistance and the effect is probably reflected by HOMA-IR. ${ }^{15}$ The relationship with SNPs was still undetermined. In conclusion, our case-control investigation in the Chinese Han population and comprehensive meta-analysis did not support a positive association

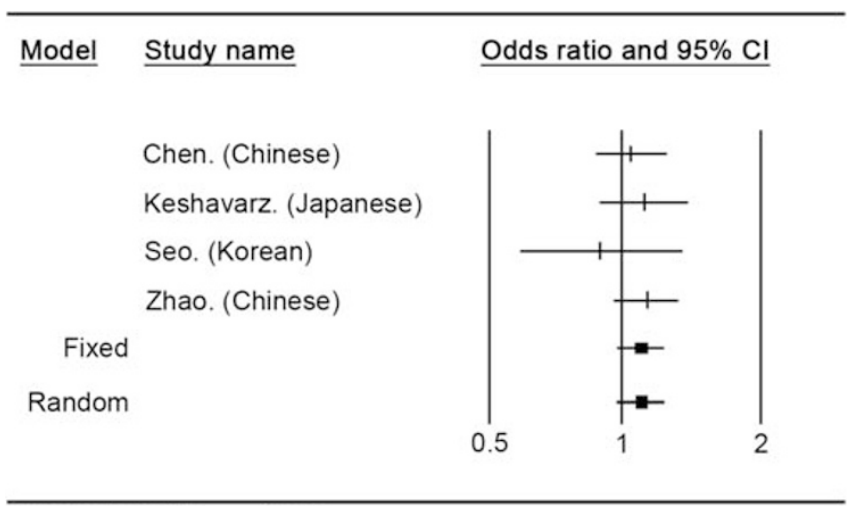

\section{ENPP1 K121Q and T2D}

Figure 2 Meta-analysis of ENPP1 K121Q and type 2 diabetes in Asian populations.

between the two SNPs rs1044498 and rs7754561 of ENPP1 and T2D or obesity. We expect that it may function as a reference point for further investigations on the effects of ENPP1 on T2D and obesity in various ethnic populations.

\section{ACKNOWLEDGEMENTS}

This work was supported by grants 2007CB947300, 07DZ22917, 2010CB529600, 2010CB529505 and 09DJ1400601, by the Shanghai Leading Academic Discipline Project (B205), the Shanghai Municipality Science \& Technology Commission (2008ZD001, 07DJ14005), the Chinese Academy of Sciences (2009KIP305) and the National Natural Science Foundation of China (30972529). 
22 Bouhaha, R., Meyre, D., Kamoun, H. A., Ennafaa, H., Vaillant, E., Sassi, R. et al. Effect of ENPP1/PC-1-K121Q and PPARgamma-Pro12Ala polymorphisms on the genetic susceptibility to T2D in the Tunisian population. Diabetes Res. Clin. Pract. 81, 278-283 (2008).

Groop, L. C. \& Tuomi, T. Non-insulin-dependent diabetes mellitus-a collision between thrifty genes and an affluent society. Ann. Med. 29, 37-53 (1997).

2 Barnett, A. H., Eff, C., Leslie, R. D \& Pyke, D. A. Diabetes in identical twins. A study of 200 pairs. Diabetologia. 20, 87-93 (1981).

3 Sladek, R., Rocheleau, G., Rung, J., Dina, C., Shen, L., Serre, D. et al. A genome-wide association study identifies novel risk loci for type 2 diabetes. Nature. 445, 881-885 (2007).

4 Scott, L. J., Mohlke, K. L., Bonnycastle, L. L., Willer, C. J., Li, Y., Duren, W. L. et al. A genome-wide association study of type 2 diabetes in Finns detects multiple susceptibility variants. Science. 316, 1341-1345 (2007).

5 Saxena, R., Voight, B. F., Lyssenko, V., Burtt, N. P., de Bakker, P. I., Chen, H. et al. Genome-wide association analysis identifies loci for type 2 diabetes and triglyceride levels. Science 316, 1331-1336 (2007).

6 Atwood, L. D., Heard-Costa, N. L., Cupples, L. A., Jaquish, C. E., Wilson, P. W. \& D'Agostino, R. B. Genomewide linkage analysis of body mass index across 28 years of the Framingham Heart Study. Am. J. Hum. Genet. 71, 1044-1050 (2002).

7 Duggirala, R., Blangero, J., Almasy, L., Arya, R., Dyer, T. D., Williams, K. L. et al. A major locus for fasting insulin concentrations and insulin resistance on chromosome $6 \mathrm{q}$ with strong pleiotropic effects on obesity-related phenotypes in nondiabetic Mexican Americans. Am. J. Hum. Genet. 68, 1149-1164 (2001).

8 Ghosh, S., Watanabe, R. M., Valle, T. T., Hauser, E. R., Magnuson, V. L., Langefeld, C. D. et al. The Finland-United States investigation of non-insulin-dependent diabetes mellitus genetics (FUSION) study. I. An autosomal genome scan for genes that predispose to type 2 diabetes. Am. J. Hum. Genet. 67, 1174-1185 (2000).

9 Xiang, K., Wang, Y., Zheng, T., Jia, W., Li, J., Chen, L. et al. Genome-wide search for type 2 diabetes/impaired glucose homeostasis susceptibility genes in the Chinese: significant linkage to chromosome 6q21-q23 and chromosome 1q21-q24. Diabetes. 53, 228-234 (2004).

10 Maddux, B. A., Sbraccia, P., Kumakura, S., Sasson, S., Youngren, J., Fisher, A. et al. Membrane glycoprotein PC-1 and insulin resistance in non-insulin-dependent diabetes mellitus. Nature. 373, 448-451 (1995).

11 Maddux, B. A. \& Goldfine, I. D. Membrane glycoprotein PC-1 inhibition of insulin receptor function occurs via direct interaction with the receptor alpha-subunit. Diabetes. 49, 13-19 (2000).

12 Goldfine, I. D., Maddux, B. A., Youngren, J. F., Frittitta, L., Trischitta, V. \& Dohm, G. L. Membrane glycoprotein PC-1 and insulin resistance. Mol. Cell. Biochem. 182, 177-184 (1998).

13 Frittitta, L., Spampinato, D., Solini, A., Nosadini, R., Goldfine, I. D., Vigneri, R. et al. Elevated PC-1 content in cultured skin fibroblasts correlates with decreased in vivo and in vitro insulin action in nondiabetic subjects: evidence that PC-1 may be an intrinsic factor in impaired insulin receptor signaling. Diabetes. 47, 1095-1100 (1998).

14 Frittitta, L., Youngren, J., Vigneri, R., Maddux, B. A., Trischitta, V. \& Goldfine, I. D. PC-1 content in skeletal muscle of non-obese, non-diabetic subjects: relationship to insulin receptor tyrosine kinase and whole body insulin sensitivity. Diabetologia. 39, 1190-1195 (1996).

15 Maddux, B. A., Chang, Y. N., Accili, D., McGuinness, O. P., Youngren, J. F. \& Goldfine, I. D. Overexpression of the insulin receptor inhibitor PC-1/ENPP1 induces insulin resistance and hyperglycemia. Am. J. Physiol. 290, E746-749 (2006).

16 Groop, L. Pathogenesis of type 2 diabetes: the relative contribution of insulin resistance and impaired insulin secretion. Int. J. Clin. Pract. 3-13 (2000).

17 Pizzuti, A., Frittitta, L., Argiolas, A., Baratta, R., Goldfine, I. D., Bozzali, M. et al. A polymorphism (K121Q) of the human glycoprotein PC-1 gene coding region is strongly associated with insulin resistance. Diabetes. 48, 1881-1884 (1999).

18 Costanzo, B. V., Trischitta, V., Di Paola, R., Spampinato, D., Pizzuti, A., Vigneri, R. et al. The $Q$ allele variant (GLN121) of membrane glycoprotein PC-1 interacts with the insulin receptor and inhibits insulin signaling more effectively than the common $\mathrm{K}$ allele variant (LYS121). Diabetes. 50, 831-836 (2001).

19 Abate, N., Chandalia, M., Satija, P., Adams-Huet, B., Grundy, S. M., Sandeep, S. et al. ENPP1/PC-1 K121Q polymorphism and genetic susceptibility to type 2 diabetes. Diabetes. 54, 1207-1213 (2005).

20 Meyre, D., Bouatia-Naji, N., Vatin, V., Veslot, J., Samson, C., Tichet, J. et al. ENPP1 $\mathrm{K} 121 \mathrm{Q}$ polymorphism and obesity, hyperglycaemia and type 2 diabetes in the prospective DESIR Study. Diabetologia. 50, 2090-2096 (2007).

21 Willer, C. J., Bonnycastle, L. L., Conneely, K. N., Duren, W. L., Jackson, A. U., Scott, L. J. et al. Screening of 134 single nucleotide polymorphisms (SNPs) previously associated with type 2 diabetes replicates association with 12 SNPs in nine genes. Diabetes. 56, 256-264 (2007).
23 Ezzidi, I., Mtiraoui, N., Cauchi, S., Vaillant, E., Dechaume, A., Chaieb, M. et al. Contribution of type 2 diabetes associated loci in the Arabic population from Tunisia: a case-control study. BMC. Med. Genet. 10, 33 (2009).

24 Chandalia, M., Grundy, S. M., Adams-Huet, B. \& Abate, N. Ethnic differences in the frequency of ENPP1/PC1 121Q genetic variant in the Dallas Heart Study cohort. J. Diabetes Complications. 21, 143-148 (2007).

25 Hamaguchi, K., Terao, H., Kusuda, Y., Yamashita, T., Hazoury Bahles, J. A., Cruz, L. M. et al. The PC-1 Q121 allele is exceptionally prevalent in the Dominican Republic and is associated with type 2 diabetes. J. Clin. Endocrinol. Metab. 89, 1359-1364 (2004).

26 Gonzalez-Sanchez, J. L., Zabena, C., Martinez-Larrad, M. T., Martinez-Calatrava, M. J., Perez-Barba, M. \& Serrano-Rios, M. Association of ENPP1 (PC-1) K121Q polymorphism with obesity-related parameters in subjects with metabolic syndrome. Clin. Endocrinol. (Oxf). (2007).

27 Rasmussen, S. K., Urhammer, S. A., Pizzuti, A., Echwald, S. M., Ekstrom, C. T., Hansen, L. et al. The K121Q variant of the human PC-1 gene is not associated with insulin resistance or type 2 diabetes among Danish Caucasians. Diabetes. 49, 1608-1611 (2000).

28 Chen, M. P., Chung, F. M., Chang, D. M., Tsai, J. C., Huang, H. F., Shin, S. J. et al. ENPP1 K121Q polymorphism is not related to type 2 diabetes mellitus, features of metabolic syndrome, and diabetic cardiovascular complications in a Chinese population. Rev. Diabet. Stud. 3, 21-30 (2006).

29 Keshavarz, P., Inoue, H., Sakamoto, Y., Kunika, K., Tanahashi, T., Nakamura, N. et al. No evidence for association of the ENPP1 (PC-1) K121Q variant with risk of type 2 diabetes in a Japanese population. J. Hum. Genet. 51, 559-566 (2006).

30 Weedon, M. N., Shields, B., Hitman, G., Walker, M., McCarthy, M. I., Hattersley, A. T. et al. No evidence of association of ENPP1 variants with type 2 diabetes or obesity in a study of 8,089 U.K. Caucasians. Diabetes. 55, 3175-3179 (2006).

31 Grarup, N., Urhammer, S. A., Ek, J., Albrechtsen, A., Glumer, C. Borch-Johnsen, K. et al. Studies of the relationship between the ENPP1 K121Q polymorphism and type 2 diabetes, insulin resistance and obesity in 7333 Danish white subjects. Diabetologia. 49, 2097-2104 (2006).

$32 \mathrm{Seo}$, H. J., Kim, S. G. \& Kwon, O. J. The K121Q polymorphism in ENPP1 (PC-1) is not associated with type 2 diabetes or obesity in Korean male workers. J. Korean. Med. Sci. 23, 459-464 (2008).

33 Gu, H. F., Almgren, P., Lindholm, E., Frittitta, L., Pizzuti, A., Trischitta, V. et al. Association between the human glycoprotein PC-1 gene and elevated glucose and insulin levels in a paired-sibling analysis. Diabetes. 49, 1601-1603 (2000).

34 Moore, A. F. \& Florez, J. C. Genetic Susceptibility to Type 2 Diabetes and Implications for Antidiabetic Therapy. Annu. Rev. Med. 59, 95-111 (2008).

35 Bei-Fan, Z. Predictive values of body mass index and waist circumference for risk of body mass index and waist circumference in Chinese adults. Asia Pac. J. Clin. Nutr. 11(Suppl 8), S685-S693 (2002).

36 Shi, Y. Y. \& He, L. SHEsis, a powerful software platform for analyses of linkage disequilibrium, haplotype construction, and genetic association at polymorphism loci. Cell Res. 15, 97-98 (2005).

37 Faul, F., Erdfelder, E., Lang, A. G. \& Buchner, A. G *Power 3: a flexible statistical power analysis program for the social, behavioral, and biomedical sciences. Behav. Res. Methods. 39, 175-191 (2007).

38 Zimmet, P., Alberti, K. G. \& Shaw, J. Global and societal implications of the diabetes epidemic. Nature. 414, 782-787 (2001).

39 Bacci, S., Ludovico, O., Prudente, S., Zhang, Y. Y., Di Paola, R., Mangiacotti, D. et al. The $\mathrm{K} 121 \mathrm{Q}$ polymorphism of the ENPP1/PC-1 gene is associated with insulin resistance/atherogenic phenotypes, including earlier onset of type 2 diabetes and myocardial infarction. Diabetes. 54, 3021-3025 (2005).

40 Moore, A. F., Jablonski, K. A., Mason, C. C. McAteer, J. B., Arakaki, R. F., Goldstein, B. $\mathrm{J}$. et al. The association of ENPP1 K121Q with diabetes incidence is abolished by lifestyle modification in the diabetes prevention program. J.clin. endocrinol. metab. 94, 449-455 (2009).

41 El Achhab, Y., Meyre, D., Bouatia-Naji, N., Berraho, M., Deweirder, M., Vatin, V. et al. Association of the ENPP1 K121Q polymorphism with type 2 diabetes and obesity in the Moroccan population. Diabetes Metab. 35, 37-42 (2009). factors of certain related diseases in Chinese adults: study on optimal cut-off points 